\title{
The effect of threatened shock upon pain threshold
}

DIANA R. HASLAM

UNIVERSITY OF BRISTOL

An experiment was carried out to assess the effect of threatened shock upon heat pain threshold. It was found that mean pain threshold was significantly lower in a group of $S$ s threatened with shock than in a control group in which there there was no threat of shock.

It has been contended by Beecher (1959) that pain experienced in a laboratory setting ("experimental pain ") is different from pain resulting from injury or disease ("pathological pain") in that experimental pain is usually unaccompanied by anxiety. However, if anxiety is introduced into the experimental situation it is found to lower the heat-pain threshold (Lepanto et al, 1965). Lepanto et al assessed pain threshold under two conditions: Ss who were able to control the stimulus ("no anxiety" condition) and Ss who had no control over the stimulus ("anxiety" condition).

Further evidence that anxiety lowers the pain threshold is provided by the experiment reported below. It was predicted that mean heat-pain threshold for a group of Ss threatened with electric shock (experimental group) would be lower than for a group without threat of shock (control group).

\section{Method}

Pain threshold was assessed by means of a HardyWolff (1952) radiant-heat apparatus. Details of this and the procedure used are given elsewhere (Haslam, 1965).

For all Ss the energy level of the first stimulus was $98 \mathrm{mcal} / \mathrm{sec} . / \mathrm{cm}^{2}$, which the majority of Ss described as warm. The intensity of each successive stimulus was increased by approximately $16 \mathrm{mcal} / \mathrm{sec} . / \mathrm{cm}^{2}$ as this has been shown by Haslam \& Thomas (in preparation) to be the optimum interval (that is, the one giving the most reliable threshold values) in the assessment of pain threshold. This procedure was continued until the $S$ reported a small stab of pain at the end of the 3-sec. exposure.

Since Hardy, Goodell, \& Wolff (1951) reported skin temperature to have a modifying influence upon pain threshold, forehead skin temperature was measured at intervals during the experiment and the values given in Table 1 are those recorded when the pain threshold was reached. Room temperature was always between $20.5^{\circ} \mathrm{C}$ and $22.0^{\circ} \mathrm{C}$.

In order to produce a state of anxiety in the experimental group, electrodes were attached to the Ss' left arms and they were told that at some time during the experiment they would receive a fairly severe electrtc shock. They were told that they would receive the shock either before or after their pain threshold had been reached; this was to prevent them from reporting pain at a low stimulus value in order to avoid electric shock. No shock was in fact given as the pain experienced might have had an effect upon heat-pain threshold. At the end of the experiment Ss were asked if they had felt anxious about receiving an electric shock.

Twenty-nine students (14 male and 15 female) served as $\mathrm{Ss}$ in the experimental group and 24 (12 male and 12 female) in the control group. The results for nine Ss were, however, not included in the experimental group (leaving a total of 20,10 male and 10 female) because they reported that they had felt no anxiety about receiving an electric shock.

\section{Results and Discussion}

The results of the experiment can be seen in Table 1.

The Mann-Whitney U Test (Siegel, 1956) showed that pain threshold was significantly lower in the experimental group than in the control group $(p<0.00016$, one-tailed). The prediction was thus confirmed.

It is interesting to note that the mean pain threshold for the nine Ss who were rejected because they had not felt anxious about the threatened shock was $245 \mathrm{mcal} /$ $\mathrm{sec} . / \mathrm{cm}^{2}$ compared with $197 \mathrm{mcal} / \mathrm{sec} . / \mathrm{cm}^{2}$ for the experimental group and $235 \mathrm{mcal} / \mathrm{sec} . / \mathrm{cm}^{2}$ for the control group.

\section{Skin Temperafure}

Hardy et al (1951) have reported that skin temperature has a modifying influence upon pain threshold such that the higher the skin temperature the lower the pain threshold. Table 1 shows that although mean skin temperature was lower in the experimental group than in the control group, mean pain threshold was also

Table 1. Mean forehead pain threshold and range under conditions of threatened shock (experimental group) compared with the results for a control group in which there was no threat of shock.

\begin{tabular}{lcccc}
$\begin{array}{l}\text { Number of } \\
\text { subjects }\end{array}$ & $\begin{array}{l}\text { Mean age of } \\
\text { subjects in years }\end{array}$ & $\begin{array}{c}\text { Mean forehead } \\
\text { skin temp in }{ }^{\circ} \mathrm{C}\end{array}$ & $\begin{array}{l}\text { Mean forehead } \\
\text { pain threshold } \\
\text { in mc. } / \mathrm{sec} . / \mathrm{cm} .\end{array}$ & $\begin{array}{l}\text { Range of forehead } \\
\text { pain threshold } \\
\text { in mc./sec./cm. }{ }^{2}\end{array}$ \\
\hline 20 & 22.4 & 33.35 & 197 & $140-247$ \\
24 & 21.6 & 33.8 & 235 & $176-302$ \\
\hline
\end{tabular}


lower. The present results do not, therefore, support those of Hardy et al.

It has been shown that anxiety can be introduced into the laboratory assessment of pain threshold and so make experimental pain more like pathological pain. Hill et al (1955) have shown that morphine relieves pain only when anxiety is present. The method described above, therefore, can be used to study the effectiveness of analgesic drugs in a laboratory setting.

\section{References}

Beecher, H. K. The measurement of subjective responses. New York: Oxford University Press, 1959.

Hardy, J. D., Goodell, H., \& Wolff, H. G. The influence of skin temperature upon the pain threshold as evoked by thermal radiation. Science, 1851, 114, 149-150.

Hardy, J. D., Wolff, H. G., \& Goodell, H. Pain sensations and reactions. Baltimore: The Williams \& Wilkins Company, 1952.

Haslam, D. R. The influence of stimulus scale-interval upon the assessment of pain threshold. Quart. J. exp.. Psychol., 1965, 17, 65-8.

Haslam, D. R., \& Thomas, E. A. C. An optimum interval in the assessment of pain threshold. (in preparation.)

Hill, H. E., Belleville, R. E., \& Wikler, A. Studies on anxiety associated with anticipation of pain. II. Comparative effects of pentobarbital and morphine. Arch. Neurol. Psychiat., 1955, 73, 602-8.

Lepanto, R., Moroney, W., \& Zenhausem, R. The contribution of anxiety to the laboratory investigation of pain. Psychon. Sci. $1965,3,475$.

Siegel, S. Nonparametric statistics for the behavioral sciences. New York: McGraw-Hill Book Company, Inc., 1956. 